Article

\title{
Development of Biodegradable Agar-Agar/Gelatin-Based Superabsorbent Hydrogel as an Efficient Moisture-Retaining Agent
}

\author{
Jyoti Chaudhary ${ }^{1}$, Sourbh Thakur ${ }^{1,2, *}$, Minaxi Sharma ${ }^{3}$, Vijai Kumar Gupta ${ }^{4, *(1)}$ \\ and Vijay Kumar Thakur 5,6,*(D) \\ 1 School of Chemistry, Faculty of Sciences, Shoolini University, Solan, Himachal Pradesh 173229, India; \\ jyotishuu26@gmail.com \\ 2 Center for Computational Materials Science, Institute of Physics, Slovak Academy of Sciences, \\ 84511 Bratislava, Slovakia \\ 3 Department of Food Technology, Akal College of Agriculture, Eternal University, Baru Sahib, \\ Himachal Pradesh 173101, India; minaxi86sharma@gmail.com \\ 4 AgroBioSciences (AgBS) and Chemical \& Biochemical Sciences (CBS) Department, University Mohammed \\ VI Polytechnic (UM6P), Lot 660, Hay Moulay Rachid, Benguerir 43150, Morocco \\ 5 Biorefining and Advanced Materials Research Center, Scotland's Rural College (SRUC), Kings Buildings, \\ West Mains Road, Edinburgh EH9 3JG, UK \\ 6 Department of Mechanical Engineering, School of Engineering, Shiv Nadar University, \\ Uttar Pradesh 201314, India \\ * Correspondence: thakursourbh@gmail.com or sourbh.thakur@savba.sk (S.T.); vijaifzd@gmail.com (V.K.G.); \\ vijay.kumar@sruc.ac.uk (V.K.T.)
}

Received: 1 May 2020; Accepted: 18 June 2020; Published: 22 June 2020

check for updates

\begin{abstract}
Downgrading in the yield of crop is due to the inadequate availability of water. The way out for this trouble is to construct synthetic resources dependent on natural polymers with great water absorption and preservation limits. The present study investigated the design of agar-agar (Agr) and gelatin (GE) copolymerized methyl acrylate (MA) and acrylic acid (AA) hydrogel (Agr/GE-co-MA/AA) as a soil conditioner for moisture maintenance in agriculture. Agr/GE-co-MA/AA hydrogel was prepared by utilizing microwave-assisted green synthesis following the most suitable reaction conditions to obtain a remarkable water swelling percentage. The fabricated Agr/GE-co-MA/AA hydrogel was investigated through field emission scanning electron microscopy (FESEM), fourier transform infrared spectroscopy (FTIR), and X-ray diffraction (XRD). The water holding capacity of the soil and sand was examined by mixing Agr/GE-co-MA/AA hydrogel with soil and sand. The result demonstrates that the water holding time extended from 10 to 30 days for soil and 6 to 10 days for sand by using Agr/GE-co-MA/AA hydrogel. This synthesized biodegradable, low-cost and non-toxic Agr/GE-co-MA/AA hydrogel shows novelty as soil water maintaining material for irrigation in agriculture.
\end{abstract}

Keywords: gelatin; agar-agar; green synthesis; hydrogel; biodegradable; swelling; soil; agriculture

\section{Introduction}

Sustainable development and growth in agriculture management of water is essential [1]. The inadequate supply of water is an exceedingly severe concern for agricultural activities [2]. Substitutes for the irrigation technique will become crucial in regions where the available water is decreasing with time [3]. Recently, absorbent material, like hydrophilic polymers, considers much concern for plant growth by maintaining the water and manure [4]. Hydrogels are characterized 
as cross-linked three-dimensional hydrophilic polymers, and have become one of the most recent interesting research topics due to their high swelling and hydrophilic nature [5]. Hydrogels are broadly recommended for agro purposes to remold water accessibility and swollen hydrogel stock water can be used for the function of plant water assimilation [6] as demonstrated in Scheme 1.

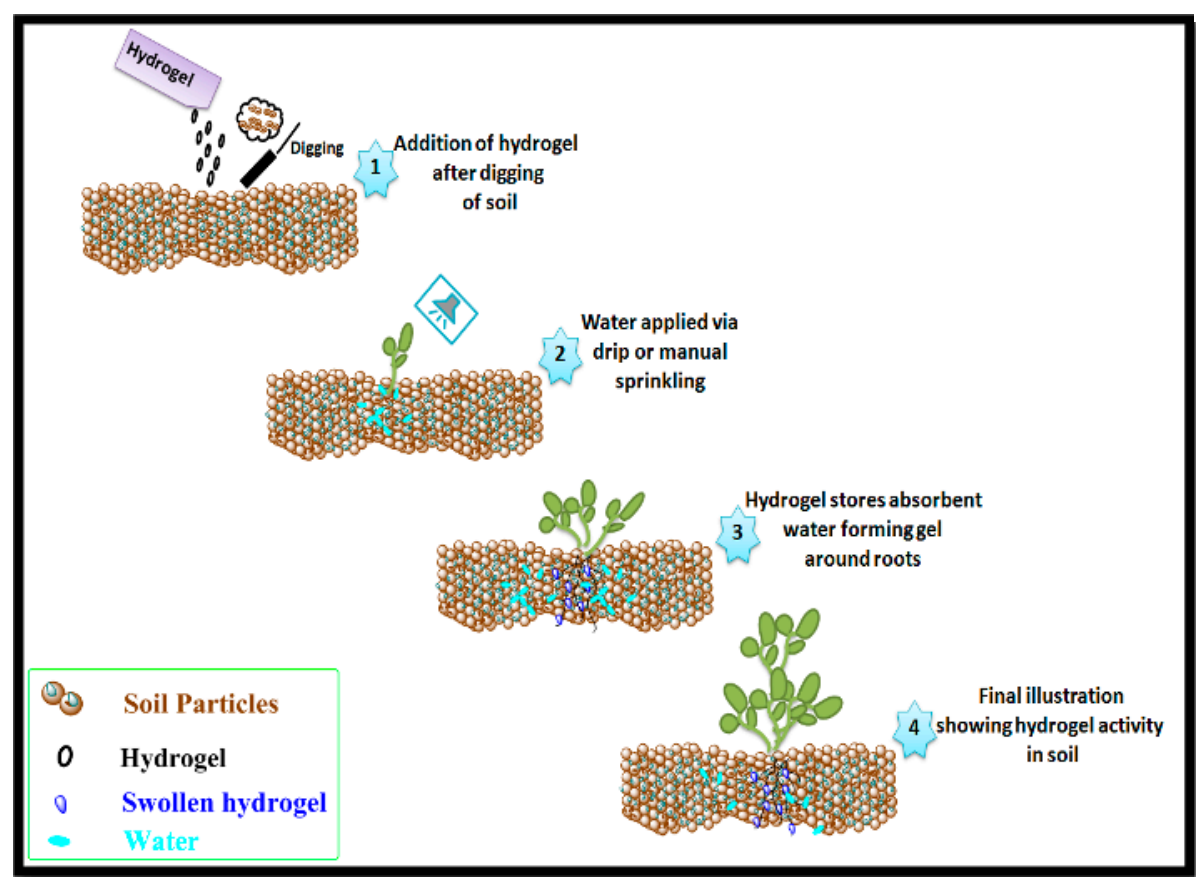

Scheme 1. Demonstrates hydrogel used in the agriculture field for the function of plant water assimilation.

Hydrogels can absorb and retain any biological fluid or aqueous media 100 times while correlating with the density [7]. The water absorption property depends upon the cross-linked arrangement and accessibility of hydrophilic units, like $-\mathrm{OH},-\mathrm{SO}_{3} \mathrm{H}$, and $-\mathrm{CONH}_{2}$ [8]. The fascinating extremely large characteristic of water makes it a remarkable material that can be used in attractive goods, such as female hygiene sanitary, diapers, soil strengthener, drug delivery systems, and hydro blockade tapes [9-12]. Because of the superb water-absorbing tendency, absorbent materials are widely exposed to soil conditioning in the field. The utilization of water-sparing materials in farming for the recovery of infertile, barren, and aired fields requires splendid attempts and potential outcomes are initiated as they decrease the irrigation water utilization and the downfall of plants, increases the soil- grip for the fertilizer, and overhaul the plant upgrade standard [5].

The absorbent material probably affects the physical characteristics of the soil, i.e., upgrading the permeability rate of the soil, and diminishing soil corrosion and runoff. The integrated dry and wet techniques applied in soil decide the efficiency of hydrogel materials [13]. The absorbent materials are layered under the soil for reasonable execution. In cultivation, they are extensively used as moisture maintenance materials and bio-remediation purposes in soil. The manufacturing of advanced goods for spraying water strategies is significant for attaining lifelong beneficial evolution, generally in the regions where the accessibility of water is less [14].

Hydrogel materials from natural polymers build up an acceptable idea, being an abundant property, low-cost production, and biodegradable in nature [5]. Agar-agar (Agr) is a gelling agent, which acts as a remarkable soil water moisture-maintaining material and improves the harvest yield. Gelatin (GE) is acquired from animal bones and is soluble in lukewarm water, having low thickness properties in comparison with agar-agar [15]. Gelatin and agar-agar based materials have been exploited in various biomedical- and environmental-related applications; however, their utilization as a substitute for a water-retaining agent in the farming field still needs to be explored. 
Agricultural synthetic polymers are common but not biodegradable and their by-products are not eco-friendly [16]. Hydrogels made from Agr/GE can be utilized as an alternative material to synthetic polymers due to their biodegradability, non-toxicity, varying solubility, controlled release characteristics, and responsiveness to microbial degradation in the environmental atmosphere [17-19]. Table 1 provides a comparative chart of synthesized agar-agar (Agr) and gelatin (GE) copolymerized methyl acrylate (MA) and acrylic acid (AA) hydrogel (Agr/GE-co-MA/AA) absorbent material to that of other reported absorbents in the literature. The Agr/GE-co-MA/AA absorbent material is efficient compared to other reported materials from the water retention ability point of view. The easy fabrication, high absorption capacity, stability, and biodegradable nature make Agr/GE-co-MA/AA hydrogel an attractive alternative for irrigation treatment in the agriculture field. The present work concentrated on microwave-facilitated synthesis of Agr/GE-co-MA/AA hydrogel for the first time as a high moisture-retaining agent.

Table 1. Comparison between water retention ratios of synthesized agar-agar/gelatin copolymerized methyl acrylate/acrylic acid (Agr/GE-co-MA/AA) hydrogel and reported absorbents.

\begin{tabular}{ccccc}
\hline S.N.* & Analysis of Media & Absorbent Material & $\begin{array}{c}\text { Water Evaporation } \\
\text { Ratio (Days) }\end{array}$ & Reference \\
\hline 1. & Soil & Alginate nanoparticles & 11 & {$[20]$} \\
2. & Sandy soil & Fenugreek galactomannan-borax hydrogel & 11.5 & {$[14]$} \\
3. & Alluvial soil & Nano clay polymer composite & 13 & {$[5]$} \\
4. & Double-coated, slow-release and & water-retention urea fertilizer & 17.3 & {$[4]$} \\
5. & Clay soil & IPN hydrogel & 27 & {$[21]$} \\
6. & Soil & Agar/Ga-Cl-poly(AA) & 28 & {$[15]$} \\
7. & Sand & Agr/GE-co-MA/AA & 10 & Present work \\
8. & Soil & Agr/GE-co-MA/AA & 30 & Present work \\
\hline
\end{tabular}

* Serial number.

The Agr/GE-co-MA/AA hydrogel swelling and water preservation properties were studied. The fabricated Agr/GE-co-MA/AA hydrogel was examined using fourier transform infrared spectroscopy (FTIR), X-ray diffraction (XRD), and field emission scanning electron microscopy (FESEM). The results of the water preservation studies demonstrate the excellent ability of Agr/GE-co-MA/AA hydrogel to maintain moisture in soil and sand for a long period.

\section{Materials and Methods}

\subsection{Materials}

Gelatin (GE) (cattle bone), agar-agar (Agr), methyl acrylate (MA) $\left(\mathrm{C}_{4} \mathrm{H}_{6} \mathrm{O}_{2}, 99 \%\right.$ ), acrylic acid (AA) $\left(\mathrm{C}_{3} \mathrm{H}_{4} \mathrm{O}_{2}, 98 \%\right), N, N^{\prime}$-methylenebisacrylamide (NMBA) $\left(\mathrm{C}_{7} \mathrm{H}_{10} \mathrm{~N}_{2} \mathrm{O}_{2}, 99 \%\right)$, and ammonium persulfate (APS) $\left(\left(\mathrm{NH}_{4}\right)_{2} \mathrm{~S}_{2} \mathrm{O}_{8}, 98 \%\right)$ were acquired from Loba Chemie, Central Drug House (Solan, India). Soil and sand were collected from the Himalayan region of North India (Shoolini University, Solan, Himachal Pradesh, India). Every single chemical was of analytical grade and utilized without future refinement. All reactions were completed utilizing deionized water.

\subsection{Synthesis of Agar-Agar/Gelatin Copolymerized Methyl Acrylate/Acrylic Acid Hydrogel}

The microwave-assisted method was used to synthesize Agr/GE-co-MA/AA. For a particular reaction, homogeneous solution of agar-agar/gelatin (1:1) was prepared in lukewarm water (temperature: $\left.39^{\circ} \mathrm{C}\right)$. In this solution, ammonium persulfate $\left(0.24 \mathrm{~mol} \mathrm{~L}^{-1}\right)$, methyl acrylate $\left(1.10 \times 10^{-2} \mathrm{~mol} \mathrm{~L}^{-1}\right)$, acrylic acid $\left(0.72 \times 10^{-2} \mathrm{~mol} \mathrm{~L}^{-1}\right)$, and $N, N^{\prime}$-methylenebisacrylamide $\left(0.16 \mathrm{~mol} \mathrm{~L}^{-1}\right)$ were added. The mixture formed was stirred for $20 \mathrm{~min}$ at room temperature to ensure homogeneity of the reaction. After the formation of the homogeneous mixture, the mixture was placed in a microwave reactor (IFB Model-20PG3S microwave oven, $1000 \mathrm{~W}$ ) operated at 20\% microwave power for $90 \mathrm{~s}$ to complete 
the polymerization reaction. The successful polymerization reaction was confirmed by the appearance of gel-like material (Agr/GE-co-MA/AA). The formed Agr/GE-co-MA/AA hydrogel was washed with acetone to remove homopolymers and dried under a hot air oven at $50{ }^{\circ} \mathrm{C}$ for $24 \mathrm{~h}$. Optimization of different reaction factors, like the initiator, monomer, solvent, cross-linker, time, and microwave power (Table 2) was carried out to obtain Agr/GE-co-MA/AA hydrogel with an excellent water absorption ability.

Table 2. Various reaction conditions for the synthesis of Agr/GE-co-MA/AA hydrogel.

\begin{tabular}{|c|c|c|c|c|c|c|c|c|}
\hline S. N. & $\begin{array}{c}\text { Initiator } \\
\text { (APS) } \\
\left(\mathrm{mol} \mathrm{L}^{-1}\right)\end{array}$ & $\begin{array}{l}\text { Reaction } \\
\text { Time } \\
\text { (s) }\end{array}$ & $\begin{array}{l}\text { Solvent } \\
\text { (mL) }\end{array}$ & $\begin{array}{c}\text { Microwave } \\
\text { power } \\
(\%)\end{array}$ & $\begin{array}{c}\text { Monomer } \\
\text { (MA) } \\
\left(\mathrm{mol} \mathrm{L}^{-1}\right)\end{array}$ & $\begin{array}{c}\text { Crosslinker } \\
\text { (NMBA) } \\
\left(\mathrm{mol} \mathrm{L}^{-1}\right)\end{array}$ & $\begin{array}{c}\text { Monomer } \\
\text { (AA) } \\
\left(\mathrm{mol} \mathrm{L}^{-1}\right)\end{array}$ & $\begin{array}{c}\% \\
\text { Swelling }\end{array}$ \\
\hline 1. & 0.15 & 70 & 5.0 & 20 & $1.10 \times 10^{-2}$ & 0.16 & - & 329.6 \\
\hline 2. & 0.19 & 70 & 5.0 & 20 & $1.10 \times 10^{-2}$ & 0.16 & - & 370.5 \\
\hline 3. & 0.24 & 70 & 5.0 & 20 & $1.10 \times 10^{-2}$ & 0.16 & - & 470.7 \\
\hline 4. & 0.28 & 70 & 5.0 & 20 & $1.10 \times 10^{-2}$ & 0.16 & - & 265.3 \\
\hline 5. & 0.32 & 70 & 5.0 & 20 & $1.10 \times 10^{-2}$ & 0.16 & - & 244.9 \\
\hline 6. & 0.24 & 50 & 5.0 & 20 & $1.10 \times 10^{-2}$ & 0.16 & - & 431.8 \\
\hline 7. & 0.24 & 70 & 5.0 & 20 & $1.10 \times 10^{-2}$ & 0.16 & - & 470.7 \\
\hline 8. & 0.24 & 90 & 5.0 & 20 & $1.10 \times 10^{-2}$ & 0.16 & - & 498.3 \\
\hline 9. & 0.24 & 110 & 5.0 & 20 & $1.10 \times 10^{-2}$ & 0.16 & - & 402.9 \\
\hline 10. & 0.24 & 130 & 5.0 & 20 & $1.10 \times 10^{-2}$ & 0.16 & - & 363.7 \\
\hline 11. & 0.24 & 90 & 3.0 & 20 & $1.10 \times 10^{-2}$ & 0.16 & - & 422.2 \\
\hline 12. & 0.24 & 90 & 3.5 & 20 & $1.10 \times 10^{-2}$ & 0.16 & - & 452.2 \\
\hline 13. & 0.24 & 90 & 4.0 & 20 & $1.10 \times 10^{-2}$ & 0.16 & - & 478.5 \\
\hline 14. & 0.24 & 90 & 4.5 & 20 & $1.10 \times 10^{-2}$ & 0.16 & - & 518.7 \\
\hline 15. & 0.24 & 90 & 5.0 & 20 & $1.10 \times 10^{-2}$ & 0.16 & - & 498.3 \\
\hline 16. & 0.24 & 90 & 4.5 & 20 & $1.10 \times 10^{-2}$ & 0.16 & - & 518.7 \\
\hline 17. & 0.24 & 90 & 4.5 & 40 & $1.10 \times 10^{-2}$ & 0.16 & - & 478.1 \\
\hline 18. & 0.24 & 90 & 4.5 & 60 & $1.10 \times 10^{-2}$ & 0.16 & - & 468.8 \\
\hline 19. & 0.24 & 90 & 4.5 & 80 & $1.10 \times 10^{-2}$ & 0.16 & - & 458.1 \\
\hline 20. & 0.24 & 90 & 4.5 & 100 & $1.10 \times 10^{-2}$ & 0.16 & - & 311.1 \\
\hline 21. & 0.24 & 90 & 4.5 & 20 & $0.55 \times 10^{-2}$ & 0.16 & - & 306.8 \\
\hline 22. & 0.24 & 90 & 4.5 & 20 & $1.10 \times 10^{-2}$ & 0.16 & - & 518.7 \\
\hline 23. & 0.24 & 90 & 4.5 & 20 & $1.65 \times 10^{-2}$ & 0.16 & - & 299.6 \\
\hline 24. & 0.24 & 90 & 4.5 & 20 & $2.20 \times 10^{-2}$ & 0.16 & - & 157.6 \\
\hline 25. & 0.24 & 90 & 4.5 & 20 & $2.75 \times 10^{-2}$ & 0.16 & - & 132.2 \\
\hline 26. & 0.24 & 90 & 4.5 & 20 & $1.10 \times 10^{-2}$ & 0.09 & - & 252.4 \\
\hline 27. & 0.24 & 90 & 4.5 & 20 & $1.10 \times 10^{-2}$ & 0.16 & - & 518.7 \\
\hline 28. & 0.24 & 90 & 4.5 & 20 & $1.10 \times 10^{-2}$ & 0.22 & - & 353.9 \\
\hline 29. & 0.24 & 90 & 4.5 & 20 & $1.10 \times 10^{-2}$ & 0.29 & - & 196.4 \\
\hline 30. & 0.24 & 90 & 4.5 & 20 & $1.10 \times 10^{-2}$ & 0.35 & - & 141.5 \\
\hline 31. & 0.24 & 90 & 4.5 & 20 & $1.10 \times 10^{-2}$ & 0.16 & $0.72 \times 10^{-2}$ & 636.1 \\
\hline 32. & 0.24 & 90 & 4.5 & 20 & $1.10 \times 10^{-2}$ & 0.16 & $1.45 \times 10^{-2}$ & 560.7 \\
\hline 33. & 0.24 & 90 & 4.5 & 20 & $1.10 \times 10^{-2}$ & 0.16 & $2.17 \times 10^{-2}$ & 525.0 \\
\hline 34. & 0.24 & 90 & 4.5 & 20 & $1.10 \times 10^{-2}$ & 0.16 & $2.91 \times 10^{-2}$ & 492.7 \\
\hline 35. & 0.24 & 90 & 4.5 & 20 & $1.10 \times 10^{-2}$ & 0.16 & $3.63 \times 10^{-2}$ & 430.2 \\
\hline
\end{tabular}

\subsection{Characterization}

Fourier transform infrared spectroscopy (FTIR) interpretations were conducted using the $\mathrm{KBr}$ pellet method in the scale of $400-4000 \mathrm{~cm}^{-1}$ using a Nicolet 5700 FTIR spectrophotometer (Agilent Technologies, L1600312; CA, USA). The morphology of Agr/GE-co-MA/AA hydrogel was measured by a field emission scanning electron microscope (FESEM) (JSM-6100). The X-ray diffraction (XRD) was assessed by a SmartLab 9kW rotating anode $\mathrm{x}$-ray (Rigaku Corporation, Tokyo, Japan).

\subsection{Swelling Studies of Agar-Agar/Gelatin Copolymerized Methyl Acrylate/Acrylic Acid Hydrogel}

The pre-weighted Agr/GE-co-MA/AA hydrogel was taken in $40 \mathrm{~mL}$ of deionized water and kept for $18 \mathrm{~h}$ at room temperature. The swollen Agr/GE-co-MA/AA hydrogel was weighed on an analytical 
balance (accuracy: $\pm 0.00001 \mathrm{~g}$ ). The swelling percentage was evaluated through the following equation [22]:

$$
\% \text { Swelling }=\frac{\mathrm{W}_{\mathrm{s}}-\mathrm{W}_{\mathrm{d}}}{\mathrm{W}_{\mathrm{d}}} \times 100,
$$

where $W_{s}$ is the weight of swollen Agr/GE-co-MA/AA hydrogel and $W_{d}$ is the weight of dry Agr/GE-co-MA/AA hydrogel.

\subsection{Water Retention Study}

Two different soil and sand media were used to perform the water retention experiments by using Agr/GE-co-MA/AA hydrogel. In a particular experiment, $2 \mathrm{~g}$ of Agr/GE-co-MA/AA hydrogel was mixed with $20 \mathrm{~g}$ of soil taken in the plastic container. Then, $40 \mathrm{~mL}$ of tap water was slowly added into the plastic container and measured $\left(\mathrm{W}_{1}\right)$ with an analytical balance (accuracy: $\left.\pm 0.00001 \mathrm{~g}\right)$. The control (soil without Agr/GE-co-MA/AA) experiment was also performed in a similar way $\left(\mathrm{W}_{2}\right)$. The analysis containers were placed at room temperature and were weighed through an analytical balance daily until no clear decrease in weight was noted. The reduction in weight was measured daily with the help of an analytical balance (accuracy: $\pm 0.00001 \mathrm{~g}$ ). The water evaporation ratio ( $\mathrm{W} \%$ ) of the soil was calculated through Equation (2) [15]:

$$
\mathrm{W} \%=\frac{\mathrm{W}_{1}-\mathrm{W}_{2}}{40} \times 100
$$

where $W_{1}$ and $W_{2}$ are the weights of the plastic container with Agr/GE-co-MA/AA hydrogel and without Agr/GE-co-MA/AA hydrogel, respectively; and 40 is the volume of water $(\mathrm{mL})$. The same experiments for sand were repeated by using sand in place of soil. The FTIR was performed for Agr/GE-co-MA/AA hydrogel fragments after the final result of moisture retention to confirm their degradable nature.

\section{Results and Discussions}

The Agr/GE-co-MA/AA hydrogel was prepared by a microwave-assisted green method involving the polymerization reaction as presented in Scheme 2.

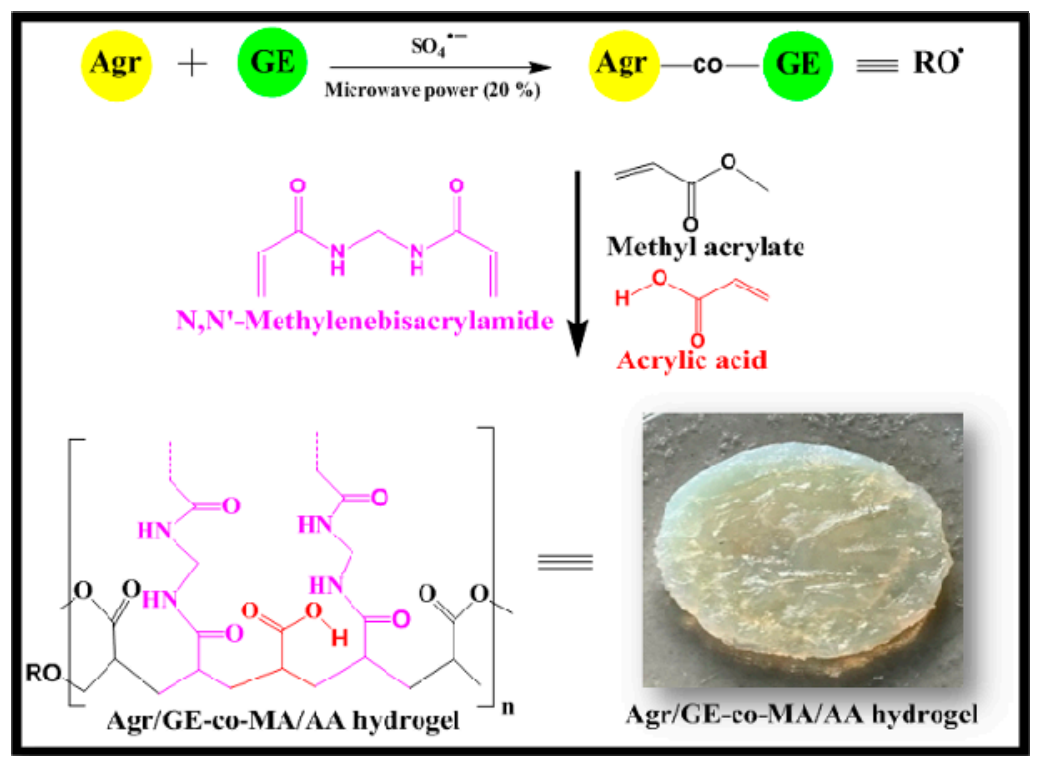

Scheme 2. Representation of the synthesis of Agr/GE-co-MA/AA hydrogel.

In general, sulfate anion radicals are produced by disintegration of APS. Subsequently, the reaction of sulphate anion radicals with MA and AA initiates the reaction with the formation of monomer 
radicals. Meanwhile, the extraction of hydrogen from Agr/GE through $\mathrm{SO}_{4}{ }^{\bullet-}$ (sulphate anion radicals) gives ${ }^{\bullet} \mathrm{O}-\mathrm{R}$ (alkoxy radicals). Thus, Agr/GE is converted to Agr/GE macro radicals followed by propagation steps. After the expansion of polymer chains, the monomer radicals that are closer to the reaction sites turn into acceptors of Agr/GE macroradicals. Accordingly, the cross-linked structure is formed during chain growth reactions by the concurrent reaction between polymer chains and vinyl groups of NMBA. Hydroxyl and other hydrophilic functional groups on Agr/GE contribute to the hydrogen bonding between Agr, GE, MA, AA, and NMBA, resulting in the formation of Agr/GE-co-MA/AA hydrogel.

\subsection{Optimization of Various Reaction Factors for the Swelling of Agar-Agar/Gelatin Copolymerized Methyl Acrylate/Acrylic Acid Hydrogel}

The outcome of the initiator concentration (APS) on the swelling percentage of Agr/GE-co-MA/AA hydrogel is shown in Figure 1a as the APS concentration varies in the range of $0.15-0.32 \mathrm{~mol} \mathrm{~L}^{-1}$. The $\%$ swelling rises with the increasing initiator concentration up to $0.24 \mathrm{~mol} \mathrm{~L}^{-1}$; subsequently, it begins to reduce. Initially, APS creates additional active sites on Agr/GE and MA/AA, resulting in the copolymerization process taking place rapidly, and leading to a rise in the percentage swelling. The higher initiator concentration support side chains and homo-polymerization processes, which are accountable for the reduction in the swelling percentage.

The effect of the reaction time on the swelling ability of Agr/GE-co-MA/AA hydrogel was analyzed in the range of 50-130 s and the outputs are presented in Figure $1 \mathrm{~b}$. The \% swelling increases with an increase in the reaction time from 50 to $90 \mathrm{~s}$, where it attains the maximum value. For the reaction time below $90 \mathrm{~s}$, Agr/GE-co-MA/AA hydrogel shows lower \% swelling, which can be ascribed to insufficient cross-linking, resulting in poor water uptake. However, when the reaction time is longer than $90 \mathrm{~s}$, excessive cross-linking occurred, which results in a more rigid structure. This ultimately leads to a poor water uptake capability [23]. The solvent volumes utilized for the formation of Agr/GE-co-MA/AA hydrogel varied from 3 to $5 \mathrm{~mL}$. The optimized value of the solvent is interpreted as $4.5 \mathrm{~mL}$ (Figure 1c). Approximately, the swelling percentage achieved at $4.5 \mathrm{~mL}$ of solvent was $518.7 \%$. Further increments in the solvent volume led to a reduction in the swelling percentage because of a reasonable decrease in the concentration of the initiator (APS), monomer, and cross-linker (NMBA), which resulted in the poor polymerization rate [24]. The impact of the microwave power on the \% swelling of Agr/GE-co-MA/AA hydrogel is presented in Figure 1d. The results demonstrated that the maximum $\%$ swelling was obtained at $20 \%$, and thereafter, it decreased. With the increase in the microwave power, the dissociation rate of APS increased, which led to the formation of a large number of radicals, which further enhanced the homo-polymerization and termination reaction; hence, the swelling percentage decreased [25]. On increasing the monomer (MA) concentration from $0.55 \times 10^{-2} \mathrm{~mol} \mathrm{~L}^{-1}$ to $1.10 \times 10^{-2} \mathrm{~mol} \mathrm{~L}^{-1}$ (Figure 1e), the rate of copolymerization increased as more MA molecules were available for chain propagation sites and thus the swelling percent was enhanced. The decrease in the swelling percentage at a higher MA concentration (beyond $1.10 \times 10^{-2} \mathrm{~mol} \mathrm{~L}^{-1}$ ) was due to the rise in the viscosity of the reaction, which prevented the movement of radicals and favored homo-polymerization over copolymerization [26]. The Agr/GE-co-MA/AA copolymer displayed the highest percentage swelling at a cross-linker (NMBA) concentration of $0.16 \mathrm{~mol} \mathrm{~L}^{-1}$ (Figure 1f). The decrease in percentage swelling with a further increase in the cross-linker concentration was due to the formation of a dense and inflexible Agr/GE-co-MA/AA hydrogel, which was not able to absorb a large amount of water [23]. The copolymer Agr/GE-co-MA/AA hydrogel shows a maximum swelling of $636.1 \%$ at the AA concentration of $0.72 \times 10^{-2} \mathrm{~mol} \mathrm{~L}^{-1}$ (Figure $1 \mathrm{~g}$ ). 
(a)

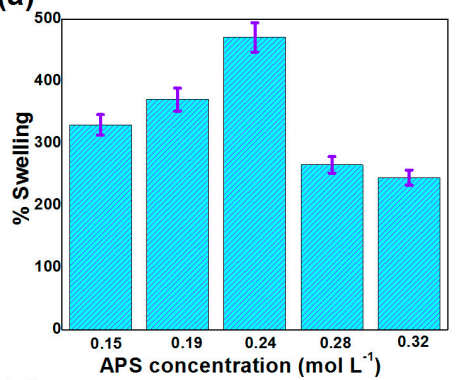

(c)

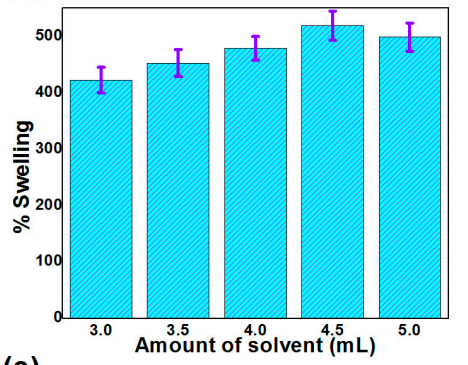

(e)

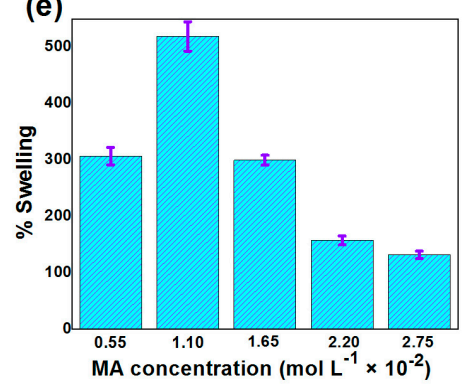

(b)

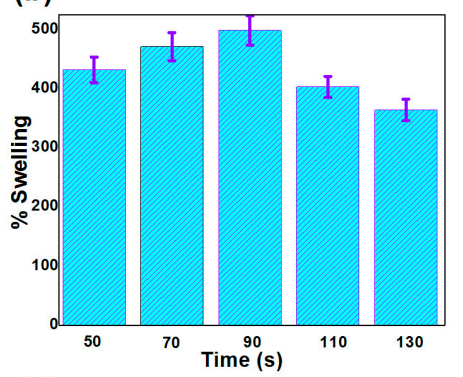

(d)
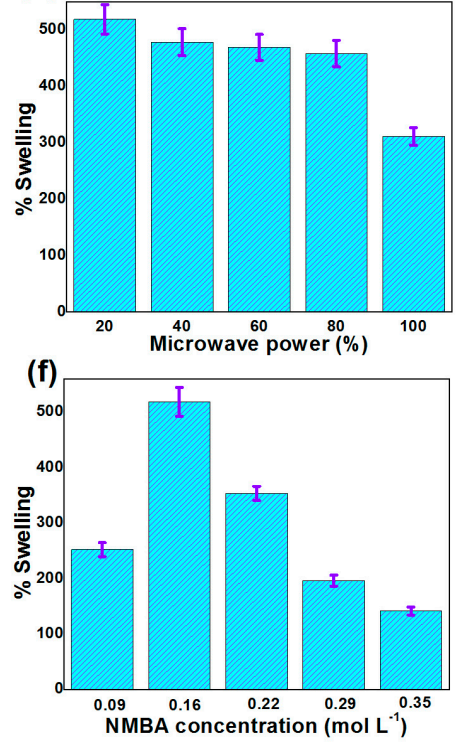

(g)

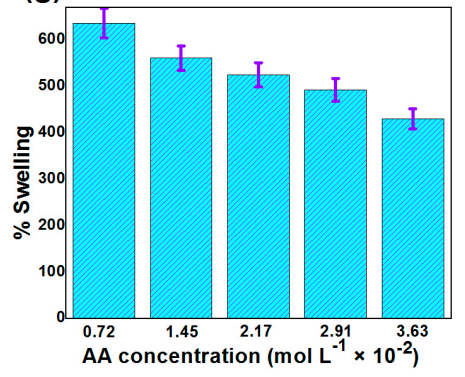

Figure 1. Swelling optimization of Agr/GE-co-MA/AA hydrogel as a function of (a) ammonium persulfate initiator, (b) reaction time, (c) solvent volume, (d) microwave power, (e) methyl acrylate concentration, (f) $\mathrm{N}, \mathrm{N}^{\prime}$-methylenebisacrylamide concentration, and (g) acrylic acid concentration.

\subsection{Characterization}

\subsubsection{Fourier Transform Infrared Analysis}

The FTIR interpretations of GE, Agr, and Agr/GE-co-MA/AA hydrogel were carried out to gain insight into the various interactions and functional groups (Figure 2).

The FTIR interpretation of GE presented peaks around 3215.2, 3361.2, and $3443.2 \mathrm{~cm}^{-1}$ corresponding to $\mathrm{N}-\mathrm{H}$ stretching of $2^{\circ}$ amide, $\mathrm{C}=\mathrm{O}$ stretching at $1651.6 \mathrm{~cm}^{-1}, \mathrm{~N}-\mathrm{H}$ bending between $1556.6 \mathrm{~cm}^{-1}$ and $1404.6 \mathrm{~cm}^{-1}, \mathrm{~N}-\mathrm{H}$ out of plane wagging at $608.8 \mathrm{~cm}^{-1}$, and $\mathrm{C}-\mathrm{H}$ stretching at 928.2 and $2846.3 \mathrm{~cm}^{-1}$ [27] (Figure 2a). The Agr showed an intense and sharp peak at 1047.7 and $890.8 \mathrm{~cm}^{-1}$ related to 3,6-anhydro galactose networks and $\mathrm{CH}_{3}$ rocking, respectively [28] (Figure 2b). The characteristic adsorption band at $1643.6 \mathrm{~cm}^{-1}$ is ascribed to the $>\mathrm{C}=\mathrm{O}$ stretching unit of AA [15] (Figure 2c). The peaks of MA at 2950.3 and $1526.6 \mathrm{~cm}^{-1}$ were due to $\mathrm{C}-\mathrm{H}$ stretching vibration and $\mathrm{C}=\mathrm{O}$ 
bonding correspondingly. Besides, the $\mathrm{C}-\mathrm{O}-\mathrm{C}$ stretching and deformation vibration were found at 1253.7 and $1123.7 \mathrm{~cm}^{-1}$, respectively, while peaks at $993.7,772.8,694.8$, and $525.8 \mathrm{~cm}^{-1}$ were due to the $\mathrm{C}-\mathrm{H}$ bending vibrations of polymer networks [29]. Some additional peaks (3380.2, 3215.2, 2950.3, 2280.4, 2176.5, and $2020.5 \mathrm{~cm}^{-1}$ ) and variation in intensity of peaks confirmed the copolymerization of MA, AA, Agr, and GE (Figure 2c).

(a)

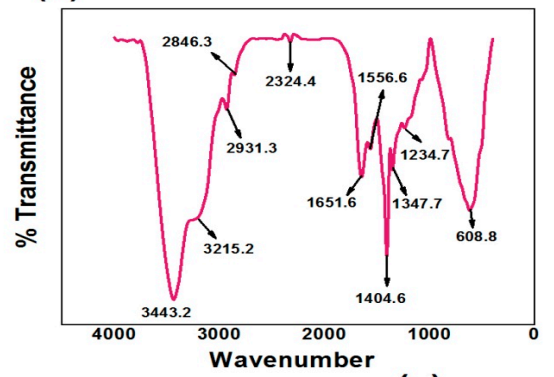

(c)

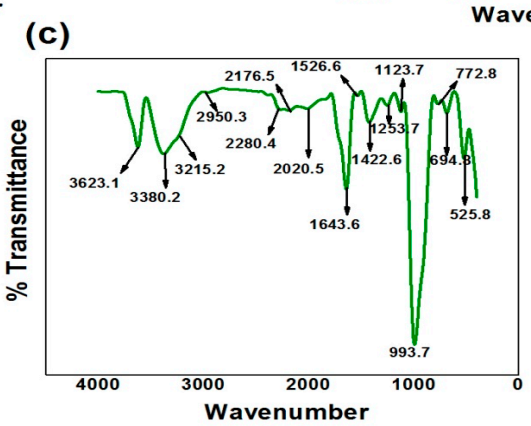

(b)

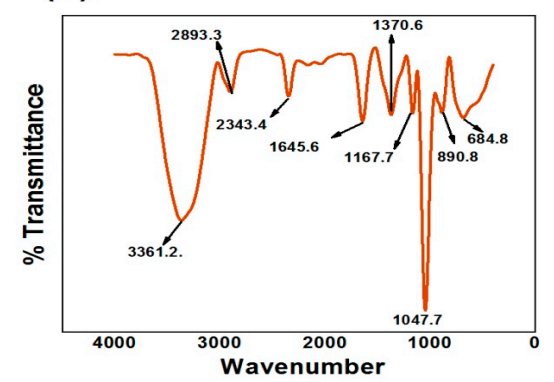

Figure 2. FTIR interpretations of (a) GE, (b) Agr, and (c) Agr/GE-co-MA/AA absorbent.

\subsubsection{X-ray Diffraction}

Gelatin shows a broad hump at $2 \theta \sim 22.5$ (Figure 3a). The XRD spectrum of Agr shows a peak at $2 \theta \sim 19.1^{\circ}$ with the intensity of 1624 (a.u), which demonstrates the semi-crystalline nature of Agr (Figure 3b). The intensity of the main diffraction peak decreased (relative intensity 1543) and shifted to the higher range (concerning Agr) $\left(2 \theta \sim 20.1^{\circ}\right)$ in the case of Agr/GE-co-MA/AA hydrogel (Figure 3c). The broadening of the spectra proposed a change towards a disordered arrangement after copolymerization.

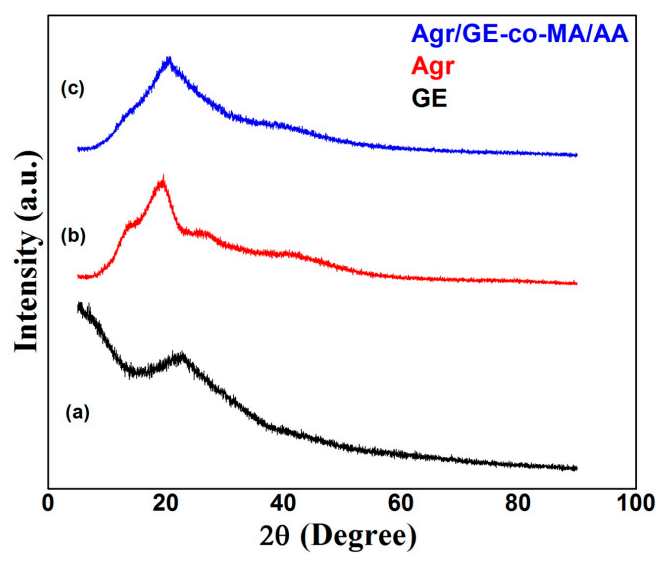

Figure 3. The XRD patterns of (a) GE, (b) Agr, and (c) Agr/GE-co-MA/AA hydrogel.

\subsubsection{Field Emission Scanning Electron Microscope}

The morphological characteristics of the Agr, GE, and Agr/GE-co-MA/AA hydrogel are displayed in Figure 4 through different magnification scales. The GE demonstrated a regular and uniform surface 
(Figure 4a,b). The Agr showed (Figure 4c,b) a smooth and compact surface morphology. The surface morphology of Agr/GE-co-MA/AA hydrogel changed into a distorted pattern with a rough and porous surface (Figure 4e,f). Hence, the Agr/GE-co-MA/AA hydrogel surface favored high water absorption.

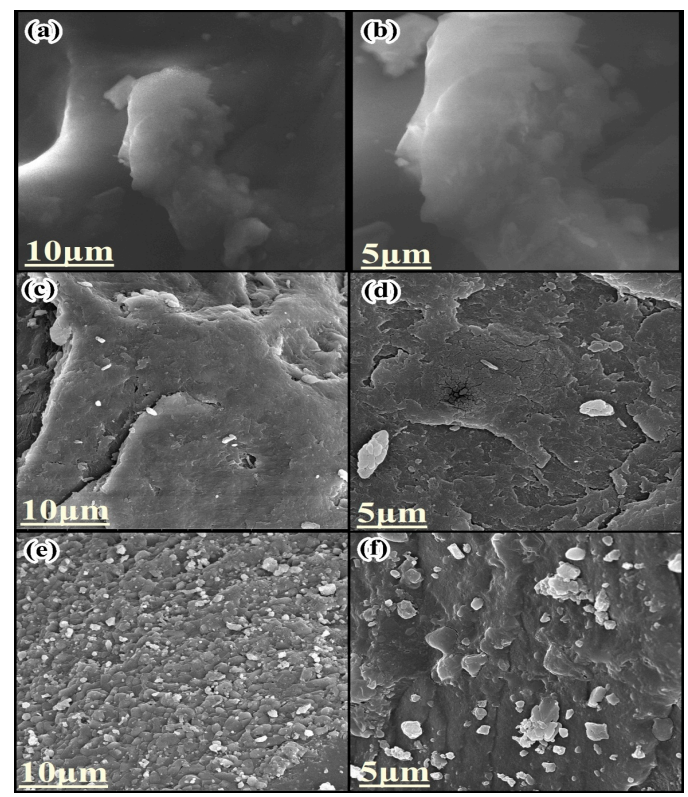

Figure 4. The FESEM morphology of (a,b) GE, (c,d) Agr, and (e,f) Agr/GE-co-MA/AA hydrogel at different magnifications.

3.3. Water Retention Properties of Agar-Agar/Gelatin Copolymerized Methyl Acrylate/Acrylic Acid Hydrogel in Soil and Sand

Nowadays, improvement in the water-holding ability of soil in cultivation is gaining extraordinary attention [16]. The pre-weighed Agr/GE-co-MA/AA hydrogel was used in soil to increase the water retention capacity. The water evaporation rate of soil and sand is shown in Figure 5.

(a)

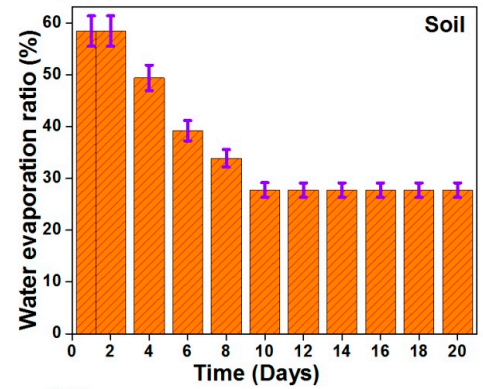

(c)

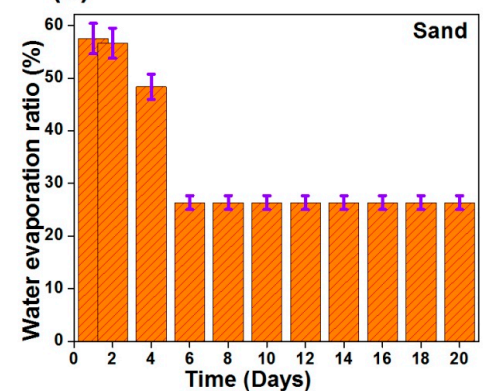

(b)

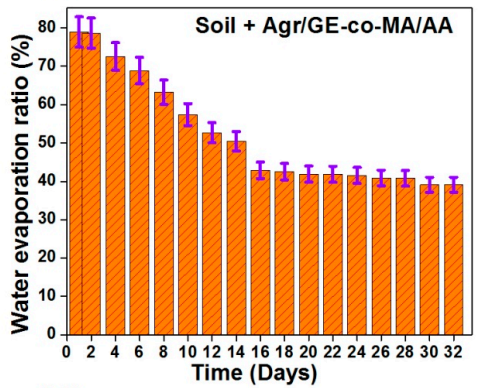

(d)

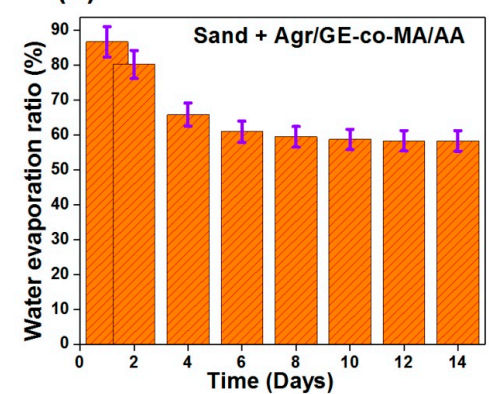

Figure 5. Water retention ratio of (a) soil, (b) Agr/GE-co-MA/AA hydrogel in soil, (c) sand, and (d) Agr/GE-co-MA/AA hydrogel in sand. 
The evaporation rate percentage in soil and sand containing Agr/GE-co-MA/AA hydrogel was less than that of the control (soil and sand without Agr/GE-co-MA/AA hydrogel). The rate of water loss was different for soil and sand, with variation in the number of days. The water evaporation levels in the soil and Agr/GE-co-MA/AA hydrogel in the soil are shown in Figure 5a,b. The water-retaining tendency for soil was increased three times when used with Agr/GE-co-MA/AA hydrogel. The sand with Agr/GE-co-MA/AA hydrogel was capable of holding the water as long as 10 days and water evaporated within 6 days in the case of sand only as presented in Figure 5c,d. The sandy loam soil can reduce moisture effortlessly in the atmosphere [30]. Thus, when Agr/GE-co-MA/AA hydrogel was sited with soil and sand, it upgraded the water-saving tendency (Scheme 3) up to 20 (soil) and 4 days (sand) extra because of the existence of a hydrophilic group, like $-\mathrm{OH},-\mathrm{CONH}$, and $-\mathrm{NH}_{2}$, in the polymeric structure of Agr/GE-co-MA/AA hydrogel [15].

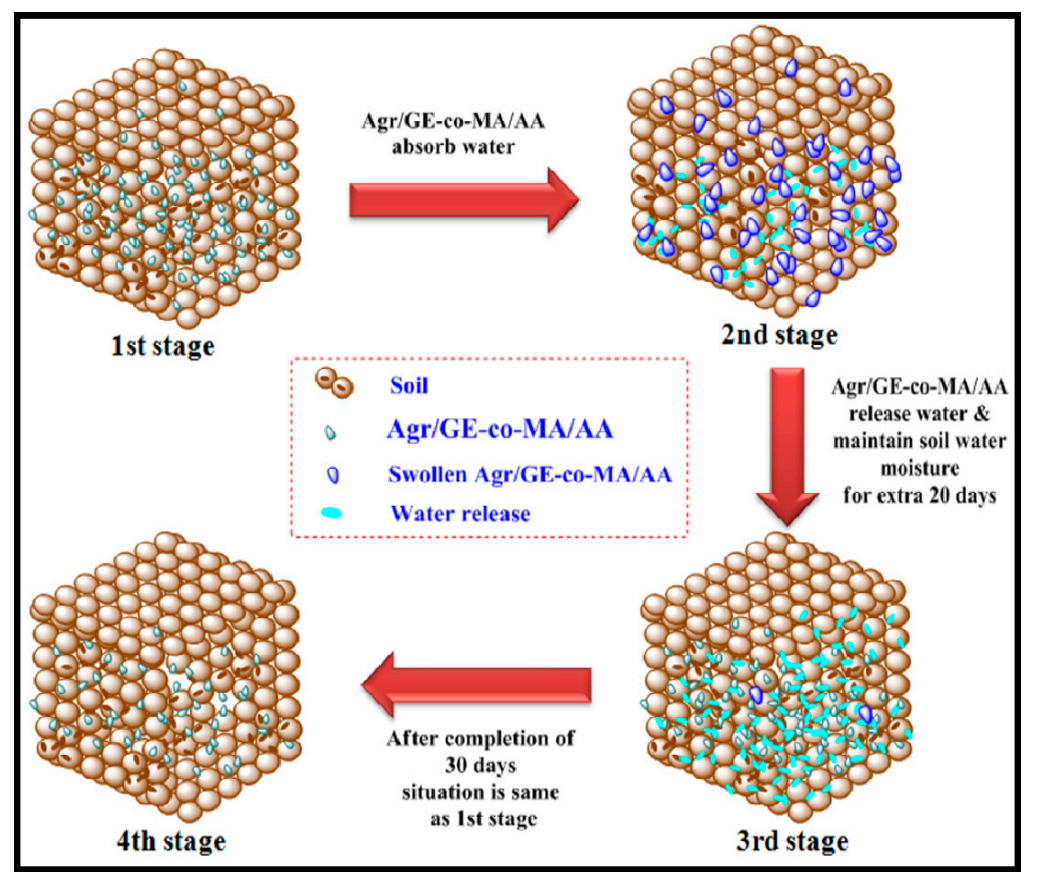

Scheme 3. Schematic presentation of water retention in the soil through Agr/GE-co-MA/AA hydrogel.

These outcomes show that the Agr/GE-co-MA/AA absorbent material can absorb and retain an immense amount of water [31]. The prepared Agr/GE-co-MA/AA hydrogel can be employed as a significant water-holding material in horticultural/agricultural applications.

\subsection{Confirmation of Agar-Agar/Gelatin Copolymerized Methyl Acrylate/Acrylic Acid Hydrogel Biodegradability via Fourier Transform Infrared Study}

The FTIR results demonstrate that Agr/GE-co-MA/AA hydrogel begins degrading in the soil as well as in sand because of bacterial indigestion and bond breaking, mainly liable for $\mathrm{H}_{2} \mathrm{O}$ discharge (Figure 6).

The characteristic peaks at 3633.1, 3339.2, 2969.3, 2334.4, 1614.6, 1414.6, 2988.3, 2884.3, 2343.4, and $1414.6 \mathrm{~cm}^{-1}$ almost vanished and the transmittance values of the bands decreased. The cross-linked network of Agr/GE-co-MA/AA hydrogel with soil and sand led to the shifting of peaks and breaking of covalent bonds [32]. The degradation of Agr/GE-co-MA/AA hydrogel in soil and sand is a direct result of the activity of microbes and microorganisms. The degradation of fabricated Agr/GE-co-MA/AA hydrogel through bacterial indigestion demonstrates that it has no harmful impacts on sand and soil fertility and enhances the organic matter in the agricultural field. 
(a)

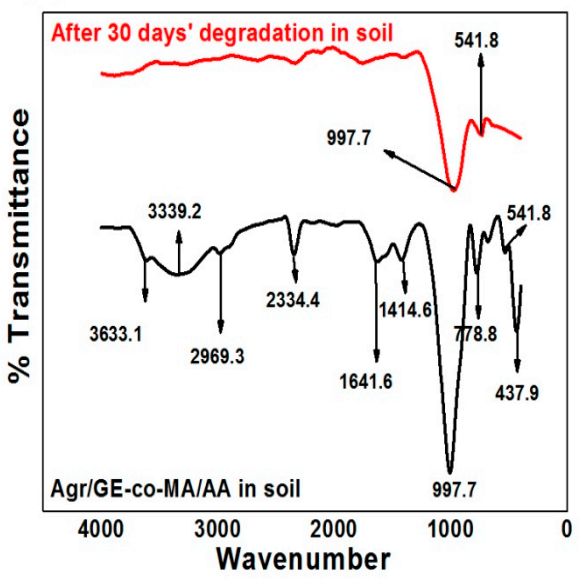

(b)

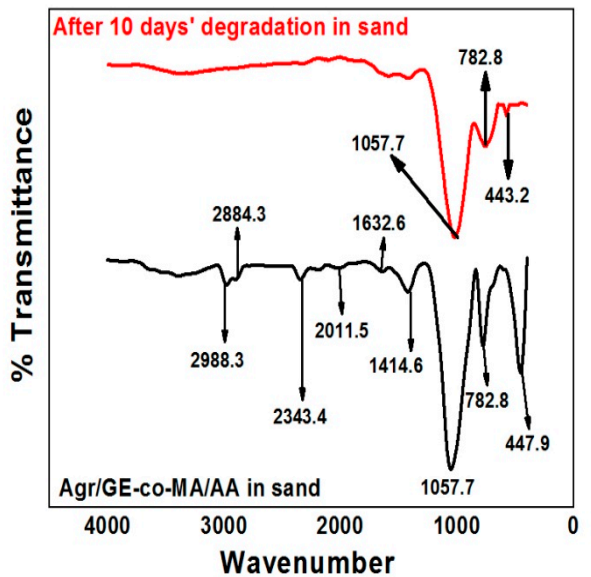

Figure 6. FTIR interpretation of Agr/GE-co-MA/AA hydrogel in (a) soil after 30 days and (b) sand after 10 days.

\section{Conclusions}

A novel biodegradable Agr/GE-co-MA/AA superabsorbent was developed as an effective water-holding agent through microwave-supported synthesis. Agr/GE-co-MA/AA hydrogel exhibited a swelling capacity of $636.1 \%$ at optimized conditions (APS $=0.24 \mathrm{~mol} \mathrm{~L}^{-1}$, time $=90 \mathrm{~s}$, solvent $=4.5 \mathrm{~mL}$, microwave power $=20 \%, \mathrm{MA}=1.10 \times 10^{-2} \mathrm{~mol} \mathrm{~L}^{-1}, \mathrm{NMBA}=0.16 \mathrm{~mol} \mathrm{~L}^{-1}, \mathrm{AA}=0.72 \times 10^{-2} \mathrm{~mol} \mathrm{~L}^{-1}$ ). The porous and rough surface of Agr/GE-co-MA/AA hydrogel favored the water retention ability of soil and sand. Agr/GE-co-MA/AA hydrogel was executed for water absorption in combination with sand and soil. Agr/GE-co-MA/AA was found to enhance the water absorption and retention ability of sand and soil effectively at a low dose of $2 \mathrm{~g}$. The water-retaining capacity of soil and sand was improved up to three times and 1.6 times, respectively. Importantly, it is useful in an economic way, and is biodegradable and non-toxic. This biodegradable Agr/GE-co-MA/AA hydrogel can be applied as a promising absorbent as a water-holding agent in agricultural applications.

Author Contributions: Experiments and original draft writing, J.C.; data analysis, J.C., S.T. and M.S.; writing, review and editing, M.S., S.T., V.K.G. and V.K.T.; supervision, S.T., V.K.G. and V.K.T. All authors have read and agreed to the published version of the manuscript.

Funding: This research received no external funding.

Acknowledgments: School of Chemistry, Faculty of Sciences, Shoolini University, Solan for financial support in characterization part.

Conflicts of Interest: The authors declare no conflict of interest.

\section{References}

1. Nada, W.M.; Blumenstein, O. Characterization and impact of newly synthesized superabsorbent hydrogel nanocomposite on water retention characteristics of sandy soil and grass seedling growth. Int. J. Soil Sci. 2015, 10, 153-165. [CrossRef]

2. Rasool, A.; Ata, S.; Islam, A.; Khan, R.U. Fabrication of novel carrageenan based stimuli responsive injectable hydrogels for controlled release of cephradine. RSC Adv. 2019, 9, 12282-12290. [CrossRef]

3. Zhang, H.; Luan, Q.; Huang, Q.; Tang, H.; Huang, F.; Li, W.; Wan, C.; Liu, C.; Xu, J.; Guo, P. A facile and efficient strategy for the fabrication of porous linseed gum/cellulose superabsorbent hydrogels for water conservation. Carbohydr. Polym. 2017, 157, 1830-1836. [CrossRef] [PubMed]

4. Liang, R.; Liu, M. Preparation and properties of coated nitrogen fertilizer with slow release and water retention. Ind. Eng. Chem. Res. 2006, 45, 8610-8616. [CrossRef] 
5. Verma, M.K.; Pandey, P.; De, N. Characterization of water retention and release capacity of innovative nano clay polymer composite superabsorbent. J. Pharmacogn. Phytochem. 2017, 6, 42-48.

6. Montesano, F.F.; Parente, A.; Santamaria, P.; Sannino, A.; Serio, F. Biodegradable superabsorbent hydrogel increaseswater retention properties of growing media and plant growth. Agric. Agric. Sci. Procedia 2015, 4, 451-458. [CrossRef]

7. Valdez-Alegría, C.J.; Fuentes-Rivas, R.M.; García-Rivas, J.L.; Zavala Arce, R.E.; Núñez, J.; de la Luz, M.; García-Gaitán, B. Synthesis of Chitosan-Polyvinyl Alcohol Biopolymers to Eliminate Fluorides from Water. Biomolecules 2020, 10, 156. [CrossRef]

8. Rizzi, V.; Romanazzi, F.; Gubitosa, J.; Fini, P.; Romita, R.; Agostiano, A.; Petrella, A.; Cosma, P. Chitosan Film as Eco-Friendly and Recyclable Bio-Adsorbent to Remove/Recover Diclofenac, Ketoprofen, and their Mixture from Wastewater. Biomolecules 2019, 9, 571. [CrossRef]

9. Sakiyama, T.; Chu, C.-H.; Fujii, T.; Yano, T. Preparation of a polyelectrolyte complex gel from chitosan and K-carrageenan and its pH-sensitive swelling. J. Appl. Polym. Sci. 1993, 50, 2021-2025. [CrossRef]

10. Yoshida, M.; Asano, M.; Kumakura, M. A new temperature-sensitive hydrogel with $\alpha$-amino acid group as side chain of polymer. Eur. Polym. J. 1989, 25, 1197-1202. [CrossRef]

11. Hogari, K.; Ashiya, F. Advances in Superabsorbent Polymers; American Chemical Society: Washington, DC, USA, 1994; p. 2639.

12. Zhang, J.; Chen, H.; Li, P.; Wang, A. Study on Superabsorbent Composite, 14: Preparation of Poly (acrylic acid)/Organo-attapulgite Composite Hydrogels and Swelling Behaviors in Aqueous Electrolyte Solution. Macromol. Mater. Eng. 2006, 291, 1529-1538. [CrossRef]

13. Austin, M.E.; Bondari, K. Hydrogel as a Field Medium Amendment for Blueberry Plants. HortScience 1992, 27, 973-974. [CrossRef]

14. Liu, C.; Lei, F.; Li, P.; Jiang, J.; Wang, K. Borax Crosslinked Fenugreek Galactomannan Hydrogel as Potential Water-retaining Agent in Agriculture. Carbohydr. Polym. 2020, 236, 116100. [CrossRef] [PubMed]

15. Hasija, V.; Sharma, K.; Kumar, V.; Sharma, S.; Sharma, V. Green synthesis of agar/Gum Arabic based superabsorbent as an alternative for irrigation in agriculture. Vacuum 2018, 157, 458-464. [CrossRef]

16. Thombare, N.; Mishra, S.; Siddiqui, M.Z.; Jha, U.; Singh, D.; Mahajan, G.R. Design and development of guar gum based novel, superabsorbent and moisture retaining hydrogels for agricultural applications. Carbohydr. Polym. 2018, 185, 169-178. [CrossRef]

17. Zohuriaan-Mehr, M.J.; Pourjavadi, A.; Salimi, H.; Kurdtabar, M. Protein-and homo poly (amino acid)-based hydrogels with super-swelling properties. Polym. Adv. Technol. 2009, 20, 655-671. [CrossRef]

18. Petre, M.; Zarnea, G.; Adrian, P.; Gheorghiu, E. Biodegradation and bioconversion of cellulose wastes using bacterial and fungal cells immobilized in radiopolymerized hydrogels. Resour. Conserv. Recycl. 1999, 27, 309-332. [CrossRef]

19. Ali, A.; Ahmed, S. Recent advances in edible polymer based hydrogels as a sustainable alternative to conventional polymers. J. Agric. Food Chem. 2018, 66, 6940-6967. [CrossRef]

20. Sharma, R.; Bajpai, J.; Bajpai, A.K.; Acharya, S.; Shrivastava, R.B.; Shukla, S.K. Designing slow water-releasing alginate nanoreserviors for sustained irrigation in scanty rainfall areas. Carbohydr. Polym. 2014, 102, 513-520. [CrossRef]

21. Sharma, K.; Kumar, V.; Kaith, B.S.; Kumar, V.; Som, S.; Kalia, S.; Swart, H.C. Synthesis, characterization and water retention study of biodegradable Gum ghatti-poly (acrylic acid-aniline) hydrogels. Polym. Degrad. Stab. 2015, 111, 20-31. [CrossRef]

22. Thakur, S.; Pandey, S.; Arotiba, O.A. Development of a sodium alginate-based organic/inorganic superabsorbent composite hydrogel for adsorption of methylene blue. Carbohydr. Polym. 2016, 153, 34-46. [CrossRef] [PubMed]

23. Chen, Y.-C.; Chen, Y.-H. Thermo and pH-responsive methylcellulose and hydroxypropyl methylcellulose hydrogels containing K2SO4 for water retention and a controlled-release water-soluble fertilizer. Sci. Total Environ. 2019, 655, 958-967. [CrossRef] [PubMed]

24. Verma, A.; Thakur, S.; Mamba, G.; Gupta, R.K.; Thakur, P.; Thakur, V.K. Graphite modified sodium alginate hydrogel composite for efficient removal of malachite green dye. Int. J. Biol. Macromol. 2020. [CrossRef]

25. Alonso, G.J.; Rivera, J.L.A.; Mendoza, A.M.M.; Mendez, M.L.H. Effect of temperature and pH on swelling behavior of hydroxyethyl cellullose-acrylamide hydrogel. e-Polymers 2007, 7. [CrossRef] 
26. Chen, J.; Zhao, Y. Relationship between water absorbency and reaction conditions in aqueous solution polymerization of polyacrylate superabsorbents. J. Appl. Polym. Sci. 2000, 75, 808-814. [CrossRef]

27. Bhowmik, S.; Islam, J.M.M.; Debnath, T.; Muhammed, Y.; Miah, M.; Bhattacharjee, S.; Khan, M. Reinforcement of Gelatin-Based Nanofilled Polymer Biocomposite by Crystalline Cellulose from Cotton for Advanced Wound Dressing Applications. Polymers 2017, 2017, 222. [CrossRef]

28. Samiey, B.; Ashoori, F. Adsorptive removal of methylene blue by agar: Effects of NaCl and ethanol. Chem. Cent. J. 2012, 6, 14. [CrossRef]

29. Mbese, J.Z.; Ajibade, P.A. Preparation and Characterization of ZnS, CdS and HgS/Poly(methyl methacrylate) Nanocomposites. Polymers 2014, 6, 2332-2344. [CrossRef]

30. Kakar, R.; Tripathi, D.; Chandel, S.; Sultanpuri, A. Distribution of micronutrient cations in relation to soil properties in Saproon Valley of Solan district in North Western Himalayas. Ann. Plant Soil Res. 2018, 20, 143-147.

31. El-Rehim, H.A.; Hegazy, E.-S.A.; El-Mohdy, H.L. Radiation synthesis of hydrogels to enhance sandy soils water retention and increase plant performance. J. Appl. Polym. Sci. 2004, 93, 1360-1371. [CrossRef]

32. Mittal, H.; Fosso-Kankeu, E.; Mishra, S.B.; Mishra, A.K. Biosorption potential of Gum ghatti-g-poly (acrylic acid) and susceptibility to biodegradation by B. subtilis. Int. J. Biol. Macromol. 2013, 62, 370-378. [CrossRef] [PubMed]

(C) 2020 by the authors. Licensee MDPI, Basel, Switzerland. This article is an open access article distributed under the terms and conditions of the Creative Commons Attribution (CC BY) license (http://creativecommons.org/licenses/by/4.0/). 